\title{
Risk Management for Overseas Development Projects
}

\author{
Shuying Li \\ SAIC-GM-Wuling Automobile Co., Ltd. \\ No.18 Hexi Road, Liuzhou, Guangxi, 545007, China \\ Tel: 86-772-375-0956 E-mail: shuying.li@sgmw.com.cn
}

\begin{abstract}
This paper identifies and assesses unique risks faced by overseas development projects in three aspects: political risk, economy/financial risk, culture risk. Response strategies are recommended to these risks. The paper also briefly discussed some integrated risk management models proposed by researchers to manage risk for overseas development projects.
\end{abstract}

Keywords: Risk management, Overseas development projects

\section{Introduction}

Overseas development projects, like any other projects, are risky. Besides the typical risks that domestic projects face, overseas development projects have unique risks. Furthermore, they are observed to have more risks and tend to have a high possibility of loss/failure (Han et al, 2007).. This is because overseas development projects are exposed to a global marketplace, in which currently sufficient information is not available but numerous uncertainties need to be considered (He, 1999).. For this reason, on one hand, risk management is becoming more emphasized in overseas projects. On the other hand, risk management is much hard in overseas development projects.

According to El-Sayegh (2007, cited Wang et al, 2004)., risk management is a formal and orderly process of identifying, analysing and responding to risks throughout the lifecycle of a project to obtain the optimal degree of risk elimination, mitigation and control. One of the most important steps in project risk management believed by many authors is the identification of risks. Once risks have been identified, it is possible to adopt action to address it (Kayis and Ahmed, 2007).

Accordingly, this paper is intent to identify and assess unique risks faced by overseas development projects and the response strategy to these risks. The paper also briefly discussed some integrated risk management models conducted by researchers to manage risk for overseas development projects.

\section{Unique Risks Faced by Overseas Development Projects}

\subsection{Overview of Unique Risks in Overseas Development Projects}

Compare with domestic projects, overseas development projects have some unique risks. A number of researches have reported different risk category that overseas business faced. Miller (1992). claimed that overseas business is facing five types of international risk: natural, societal, legal, political and governmental. Khattaba, Anchorb and Daviesb (2007). contend that political risk, in its wider context, should contain societal and legal risks. Therefore, the classification of general types of risks in international business can be reduced to four main types: political risks, financial risks, cultural risks and natural risks. However, there is not a universal category of risks in overseas business (Nawaz and Hood, 2005).. This is because that similar project may have totally different risk characteristics in different countries as the economic, political, social and cultural conditions are different.

\subsection{Political Risk and Response Strategy}

In business, there are various definitions to political risks. Among these, Howell (2001). 's definition is regarded as the representative. He defines political risk as political decisions, political events or societal events in a country will impact the business climate, which lead to investors losing money or not make as much money as they expected when the investment was made. Political risk includes "inconsistency in policies, changes in laws and regulations, restrictions on fund repatriations, and import restrictions"(Ozorhon et al, 2007)..

Political risk is the most obvious risk when projects exposed in international environment (Khattaba, Anchorb and Daviesb, 2007).. Overseas projects normally need to take a few years to complete, but the host country's political leaderships might be changed during that period, this situation will affect overseas project's completion. Moreover, Ling and Hoi (2006). argue that in order to protect local counterparts, the host country will adopt some policy to restrain foreign investment. These policies include "limitation foreign ownership on development projects or getting foreign 
participants to undertake disproportional amount of risk". For example, in India, political leaders who want to show their concern and careness for local business may not welcome foreigners in an election year. Similarly, basing on a research on Jordanian's international projects, Khattaba, Anchorb and Daviesb (2007). conclude that in Middle East area, international projects are more concerned about "host-society and interstate related risks than host-government related risks". Political risk accompanied with international projects is a significant threat to most Jordanian's international projects.

All the risk management experts felt that it is the most difficult thing for overseas business to mitigate political risk because political changes are hard to predict. Ling and Hoi (2006). suggest some clues for overseas development projects stakeholders to follow to reduce political risks. First of all, when evaluate and select overseas development projects, project location need to be carefully selected to avoid "political hotspots". Secondly, select projects with shorter duration are proved better than those with long-duration to reduce the potential political risks. Next, to those new entrants, reduce participating in government projects instead of seeking opportunities in the private sector to avoid involving in political competitions. Finally, cooperate and keep good relationships with the local government to obtain government's guarantees. At the same time, buying insurance for political risks to get compensation if hazard happen.

\subsection{Economy/Financial Risk and Response Strategy}

One of the main purposes for companies venturing overseas is to achieve the pre-determined financial rewards. But if economic and financial factors are not properly managed, can lead to bankruptcy (Kangari, 1995).. Ozorhon et al (2007). describe financial factor as the host country's macroeconomic conditions, which include fluctuations in economic conditions, inflation, and foreign exchange rates. They also argue that macroeconomic conditions will strongly affect the overall performance of international joint ventures. Similarly, El-Sayegh (2007). maintains that in United Arab Emirates (UAE)., the significant risks in international construction industry is economic risks such as inflation and fluctuating prices, material shortage and labour supply shortage. In addition, Ling and Hoi (2006). state that "the repatriation of profits back to the home country" is another financial risk. Overseas projects need to pay tax twice: on the profit earned and on the remittance of monies back to the home country. This reduces the profitability of projects.

Ozorhon et al (2007). suggest that to mitigate the economy/financial risks, an effective method is to make sure "...the contract between the owner and the joint ventures is unambiguous and the duties, responsibilities and liabilities of the parties are clearly stated at the start of the project". He (1999). claims that allocating risks through contracts is a very normal method in overseas projects practice. Some risks, which include "interest rate fluctuation, inflation, foreign currency exchange rate fluctuation, tax rate increase, funding/payment shortage..." can be allocated to the local employer, local owner or the local subcontractors. In specific, Wang et al (2001). suggest that to cope with the risk comes from currency fluctuation, firms can carefully plan which currency of payment should use in the contract. "It is possible to sign a dual-currency contract, with one portion to be paid in local currency and the rest paid in foreign currency". In addition, Dey and Ogunlana (2001). maintain that some of the financial risks such as inflation and the exchange rate must be analysed from a political aspect, because these risks can be greatly affected by stability of the host country and economic policies. Therefore, methods to reduce political risks can mitigate financial risks as well.

\subsection{Cultural Risk and Response Strategy}

Cultural risk is another significant risk to overseas development projects. Any company, which wants to carry out or manage a project successfully in other country, should be able to know the culture of the host country clearly. Cultural risk, if not properly understood, can bring misunderstandings and inefficient working (Low and Shi, 2001).. When companies carry out overseas projects, they are normally involved in a temporary project team that people come from different nationalities. Different culture, different language, different background and different perspective will make it extremely hard to keep good communication between team players. For example, according to a study conducted by Ling and Hoi (2006)., when Singapore's AEC (architecture, engineering and construction). firms undertake construction projects in India; it was found that there is significant cultural difference between foreigners and Indians.

When dealing with culture risks, Ling and Hoi (2006). state that foreign firms operating in other country should not try to change the way of the host country's working. Instead, foreigners should understand and appreciate local culture and practices. Moreover, foreigners should be flexible and extremely patient to local people. In these ways, foreigners can win local population's trust and receive friendly treatment from them.

Pheng and Leong (2000). claim that project manager is the key person when coping with culture risks. They argue that project managers in the international marketplace should have five kinds of skills: communication, leadership, interpersonality, adaptability and flexibility. Without these skills, overseas project managers may fail to tackle cultural problems, which can cause unnecessary costs/losses to their companies. In a word, project managers should be fluent in cross-cultural management. They should together with other team members to identify primary cultural differences and then adopt considerate measures to achieve project performance.

Low and Shi (2001). also suggest that overseas project manager with cross-cultural working experience is essential. If 
overseas project managers have ever been working in the host country, they can know the culture of the host country better. This knowledge will probably help them to avoid cultural misunderstanding between themselves and their foreign staffs. Therefore, to choose overseas project manager, who has previous working experience in the host country, is an effective method to mitigate culture risks.

\section{Integrated Risk Management Model/Method for Overseas Development Projects}

As to a specific project, although some of the individual risk factors may be more significant than the others, the project success rely on a company's ability to combine all risks and figure out integrated response strategy (Dikmen, Birgonul and Han, 2007).. In addition, during the whole project lifecycle, every overseas development project has different types of risks in each phase; it is important to satisfy the particular needs of a specific phase (Han et al, 2007).. However, to identify and assess all the overseas projects risks and their relationships is a very complicated, expensive and time-consuming process. This process is almost unreality for the majority of projects (He, 1999).. In these senses, using integrated risk management model to identify and control those vital risk factors is essential.

There are a lot of models proposed for overseas project risk assessment. Han et al (2007). suggest a web-based integrated risk management system. They claim the system is able to constantly check and monitor various risks that arise through the life cycle of a project, "... anyone can access the system anywhere in the world, anytime, with any device". Dikmen, Birgonul and Han (2007). recommend a fuzzy risk assessment model to rate cost overrun risk in international construction projects. The model was tested in an international construction company's overseas project in Turkey. It was found that the proposed methodology could be easily applied by the experts to quantify risk ratings. It can provide the company guidelines of the amount of risk premium. He (1999). also develops an effective method to combine risk probability analysis with risk impact assessment to identify and control vital risk in overseas construction projects. All the studies indicate that integrated risk management models are believed can help companies make better decision when carring out overseas development projects. Companies should choose comprehensive models according to the real situation of their projects.

\section{Conclusion}

This report explores the unique risks faced by overseas development projects and how to respond to those risks. The unique risks faced by overseas development projects include political risk, economic / financial risk and cultural risk. Among these risks, political risk is the most difficult to mitigate. To mitigate it, overseas project stakeholder should locate and choose overseas projects carefully. Cooperating and keeping good relationships with the local government are also necessary. Economy/Financial risk includes interest rate fluctuation, inflation, foreign currency exchange rate fluctuation, tax rate increase etc. Effective risk responds such as considerate contract and allocate risk to partners are presented. Culture risk is another significant risk. To mitigate culture risk, foreigners should understand and respect local culture. Appointing overseas project manager who is good at cross-culture management and has previous working experience in host country are also useful. In order to manage different types of risks in each phase of project lifecycle and to identify vital risk in overseas project, integrated risk management models should be tailored to help companies make better decision in pursuing overseas development projects. However, every overseas development project is unique, the risk response methods used in overseas projects should also vary from project to project, and should be very flexible in terms of their operation.

\section{References}

Dey, P.K., and Ogunlana, S. O. (2004). 'Selection and application of risk management tools and techniques for build-operate-transfer projects', Industrial Management \& Data Systems, Volume 104 Number 42004 pp. 334-346, Full text [online]. Available at: Emerald (Accessed: 06th January 2008).

Dikmen, I., Birgonul, M. T. and Han S. (2007). 'Using fuzzy risk assessment to rate cost overrun risk in international construction projects' International Journal of Project Management, Volume25, Issue 5, July 2007, Pages 494-505, Full text [online]. Available at: SeienceDirect (Accessed: 9th January 2008).

El-Sayegh, S. M. (2007). 'Risk assessment and allocation in the UAE construction industry', International Journal of Project Management, Article in Press. Full text [online]. Available at: SeienceDirect (Accessed: 06th January 2008).

Han, S. H., Kim, D.Y., Kim, H., and Jang, W. (2007). 'A web-based integrated system for international project risk management', Automation in Construction, Volume 17, Issue 3, March 2008, Pages 342-356, Full text [online]. Available at: SeienceDirect (Accessed: 17th January 2008).

He, Z. (1995). 'Risk management for overseas construction projects', International Journal of Project Management, Volume 13, Issue 4, August 1995, Pages 231-237, Full text [online]. Available at: SeienceDirect (Accessed: 8th January 2008).

Howell, L. (2001)., The handbook of country and political risk analysis (3rd ed.)., The Political Risk Services Group, USA. 
Kangari, R. ( 1995)., 'Risk management perceptions and trends of US construction', J Construct Eng Manage 121 (4)., pp. 422-429. Full text [online]. Available via CrossRef (Accessed: 15th January 2008).

Kayis, B. and Ahmed, A. (2007). 'IRMAS - development of a risk management tool for collaborative multi-site, multi-partner new product development projects', Journal of Manufacturing Technology Management, Volume 18 Number 42007 pp. 387-414, Full text [online]. Available at: Emerald (Accessed: 06th January 2008).

Khattaba, A. A., Anchorb, J. and Daviesb, E. (2007).. 'Managerial perceptions of political risk in international projects', International Journal of Project Management, Volume 25, Issue 7, October 2007, Pages 734-743, Full text [online]. Available at: SeienceDirect (Accessed: 8th January 2008).

Ling, F. Y. Y and Hoi, L. (2006). 'Risks faced by Singapore firms when undertaking construction projects in India', International Journal of Project Management, Volume 24, Issue 3, April 2006, Pages 261-270, Full text [online]. Available at: SeienceDirect (Accessed: 10th January 2008).

Low, S. Ph., Shi, Y. (2001). 'Cultural influences on organizational processes in international projects: two case studies', Work Study, Volume 50 Number 72001 pp. 276-285, Full text [online]. Available at: Emerald (Accessed: 16th January 2008)..

Miller, K. (1992). A framework for integrated risk management in international business, J Int Business Stud 2 (1992)., pp. 311-331, Full text [online]. Available at: Palgrave Macmillan (Accessed: 8th January 2008).

Nawaz, M.S. and Hood, J. (2005). 'Managing international business risk - political, cultural and ethical dimensions: a case study approach', J Insurance Res Practice 20 (1). , pp. 16-24.

Ozorhon, D., Arditi, D., Dikmen, I. and Birgonul, M. T. (2007). 'Effect of host country and project conditions in international construction joint ventures', International Journal of Project Management Volume 25, Issue 8, November 2007, Pages 799-806, Full text [online]. Available at: SeienceDirect (Accessed: 15th January 2008).

Pheng, L. S., Leong, C. H. Y. (2000). 'Cross-cultural project management for international construction', International Journal of Project Management, Volume 18, Issue 5, 1 October 2000, Pages 307-316, Full text [online]. Available at: SeienceDirect (Accessed: 15th January 2008).

Wang, S.Q., Tiong, R.L.K., Ting, S.K. and Ashley, D. (2000). 'Evaluation and management of foreign exchange and revenue risks in China's BOT projects, Construct Manage Econ 18 (2000)., pp. 197-207, Full text [online]. Available at: Emerald (Accessed: 06th January 2008). 